\section{Moderate altitude has no effect on choice reaction time in international rugby players}

\author{
Ronan E O'Carroll, Donald MacLeod
}

\begin{abstract}
There are only a few conflicting reports on the effects of moderate altitude on cognitive factors that could affect sporting performance. An investigation of choice reaction time in international rugby players at various altitudes was therefore carried out. The results suggest that moderate altitude has no significant effect on this parameter in highly trained competitive athletes.

(Br F Sports Med 1997;31:151-152)
\end{abstract}

Keywords: altitude; rugby players; performance

While it is well demonstrated that high altitude environments can result in psychological changes in unacclimatised individuals, relatively little research has been carried out into the effects of moderate altitude on cognitive factors that could affect sporting prowess. ${ }^{1}$ For example, very slight impairment of concentration and reaction time may result in devastating effects on top quality athletic performance. The literature appears to indicate that increasing altitude is associated with prolongation of reaction time, ${ }^{23}$ particularly above $4000 \mathrm{~m}$, although at more moderate altitudes, investigators have reported either no effect, ${ }^{4}$ or, paradoxically, slight improvements in psychomotor performance. ${ }^{5}$ Most of these studies have focused on extreme altitudes. Denison et $a l,{ }^{6}$ however, reported decrements in choice reaction time and learning at $2438 \mathrm{~m}$, but more recently Paul and Fraser ${ }^{7}$ found no impairment at $3658 \mathrm{~m}$.

As there appeared to be a relatively scant and conflicting literature on the subject, we carried out an empirical investigation of the effects of moderate altitude on choice reaction time in international rugby players, at sea level, during acclimatisation and before competitive play at altitude in South Africa.

Psychology, University of Stirling, Stirling FK9 4LA, United

Kingdom

R E O'Carroll

West Lothian NHS

Trust, St John's

Hospital at Howden,

Livingston EH54 6PP

United Kingdom

D MacLeod

Correspondence to: Dr O'Carroll.

Accepted for publication

\section{Methods}

Twenty six members of the Scottish international rugby squad participated as subjects. All were men of mean (SD) age 27.9 (3.4) years. The experiment involved a within subject repeated measures design. Each subject was assessed on five occasions: on two occasions in Edinburgh, Scotland, in order to provide baseline data at sea level (assessment 1 on 21 April 1995, assessment 2 on 29 April 1995), in Spain in the Pyrenees at an altitude of $1000 \mathrm{~m}$ in order to provide some degree of
Howden Road West, 18 December 1996 acclimatisation (assessment 3 on 4 May 1995) and twice in Pretoria, South Africa (assessment 4 on 23 May 1995 and assessment 5 on 10 June 1995) at an altitude of $1600 \mathrm{~m}$. Choice reaction time was measured using a Toshiba Lap Top IBM compatible portable computer. The Continuous Performance Task as described by Frith et $a l^{\beta}$ was employed. Briefly, a series of large letters appeared in the middle of the computer screen at a rate of one per second. The subjects were instructed to press the space bar of the computer as quickly as they could whenever they saw an $\mathrm{X}$ but not to press the space bar when presented with any other letter, thus measuring choice reaction time. The letters appeared in a random order. The mean time taken to respond to ten Xs per subject was recorded in milliseconds.

\section{Results}

Figure 1 shows the results in a graphical form. There was no significant effect of time, altitude, or repeat assessment on choice reaction times: Edinburgh 1 (sea level) mean $(\mathrm{SD})=323.8$ (43.2) milliseconds; Edinburgh 2 (sea level) 324.5 (43.6) milliseconds; Spain $(1000 \mathrm{~m}) 325.6$ (31.4) milliseconds; South Africa 1 (1600 m) 316.1 (31.0) milliseconds; South Africa $2(1600 \mathrm{~m}) 316.7$ (39.2) milliseconds; repeated measures analysis of variance, $F$ $=1.07, \mathrm{P}=0.38$.

\section{Discussion}

In this study we carried out assessments of choice reaction time in international rugby

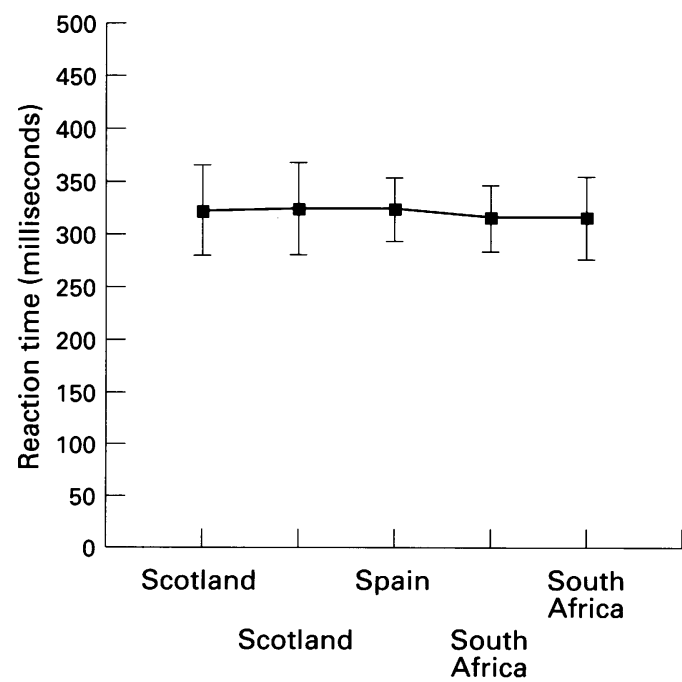

Figure 1 Effect of altitude on choice reaction time in international rugby players. 
players on five occasions, twice at sea level, in order to create a baseline, and then again at $1000 \mathrm{~m}$ for acclimatisation and twice at $1600 \mathrm{~m}$. There was no effect of time, repeat assessment, or altitude on choice reaction time. The results of this study therefore suggest that moderate altitude has no significant determinable effect on choice reaction time in highly trained international competitive athletes. It is possible that altitude did result in an increase in choice reaction time, but that this was cancelled out by the effects of practice/repeat assessment. We think this an unlikely explanation, as there was no significant improvement between assessments 1 and 2 (the baseline), where the greatest practice effects would have been expected. As stated in the Introduction, clear deleterious effects on psychomotor speed can be observed above $4000 \mathrm{~m}$. However, it is still possible that subtle effects may occur at lower altitudes, but more sensitive measures would be needed to determine them.
We thank the players who represented Scotland in the 1995 World Cup for their participation. We also thank the Scottish Rugby Union Committee and the team management for their support. D M is also grateful to Professor Craig Sharp for help in reviewing the relevant literature. Finally, we would like to thank Norma Brearley for careful preparation of the manuscript.

1 Bahrke MS, Shukitt-Hale B. Effects of altitude on mood, behaviour and cognitive functioning. A review. Sports Med 1993;16:97-125.

2 Mackintosh JH, Thomas DJ, Olive JE, Chesner IM, Knight RJE. The effect of altitude on tests of reaction time and RJE. The effect of altitude on tests of reaction tim
alertness. Aviat Space Environ Med 1988;59:246-48.

3 Ledwith F. The effects of hypoxia on choice reaction time Ledwith F. The effects of hypoxia on choice reaction

and movement time. Ergonomics 1970;13:465-82.
Phillips LW, Griswold RL, Pace N. Cognitive changes at Phillips LW, Griswold RL, Pace N. Cogn
high altitude. Psychol Rep 1963;13:423-30

5 Kelman GR, Crow TJ, Bursill AE. Effect of mild hypoxia on mental performance assessed by a test of selective attention. Aerospace Medicine 1969;40:301-3.

6 Denison DM, Ledwith F, Poulton EC. Complex reaction times at simulated cabin altitudes of 5000 feet and 8000 feet. Aerospace Medicine 1966;37:1010-13.

7 Paul MA, Fraser WD. Performance during mild acutehypoxia. Aviat Space Environ Med 1994;65:891-89.

8 Frith CD, Leary J, Cahill C, Johnstone EC. Disabilities and circumstances of schizophrenic patients: a follow-up study. IV. Performance on psychological tests. Demographic and clinical correlates of the results of these tests. Br f Psychiatry 1991; 159(suppl):26-9.

\section{The shirt sign}

I wish to describe "The shirt sign"-a new clinical sign in steroid abuse. This is a clinical observation made during examination of the respiratory system of known anabolic steroid users. The sign refers to the mode of removal of the shirt and may be of two varieties.

The T-shirt. Instead of reaching behind the neck and pulling the T-shirt over the head in a haphazard and often undignified fashion, the steroid user crosses his arms in front of his body to grip the lower hem of his shirt and removes it in a graceful, flowing motion accompanied by progressive isometric contraction of the exposed upper body musculature.

The buttoned shirt. Patients usually loosen the top two buttons and then rapidly pull the shirt over the head. The steroid user slowly unbuttons from the top downwards while increasingly contracting latissimus dorsi and pectoralis major and, occasionally, deltoid muscles. This causes some difficulty in the undoing of the lower buttons as they disappear from view below the hypertrophied muscles. With the aforementioned muscles contracted, upper limb movement also becomes more restricted.

Auscultation of the respiratory system can be difficult as patients find it impossible to inhale fully and exhale smoothly while maintaining an impressive pose.

These observations are based on only two patients and I require validation in large scale case-control and prospective studies.

BRUCE THOMPSON

6 Connaught Park Lurgan

$N$ Ireland BT66 7AZ 